\title{
Creep strain measurements using an Alternating Current Potential Drop method: A Non- destructive approach
}

\author{
C.M. Omprakash ${ }^{* 1}$, A. Kumar ${ }^{1}$, R.N. Ghosh ${ }^{2}$, A. Sridhar ${ }^{1}$, B.Srivathsa ${ }^{1}$, D.V.V. Satyanarayana ${ }^{1}$ \\ IDefence Metallurgical Research Laboratory, PO Kanchanbagh, Hyderabad, Telangana500058, India \\ 2Indian Institute of Technology, Kharagpur-721302, India \\ *E-mail address: prakash6y@gmail.com
}

Received date: April 2016

Accepted date: May 2016

\begin{abstract}
Online assessment of the state of creep damage of a component in service is very useful in ensuring safety of structures, estimation of remaining life for life extension programs. Thus, in-situ monitoring of the progress of creep damage in such components is very important and a challenging task. Alternating current potential drop (ACPD) technique along with Linear Variable Differential Transducers (LVDT's) was employed to measure voltage drop during creep tests of Alloy 718 at $600-700^{\circ} \mathrm{C}$ and $600-750 \mathrm{MPa}$. The $A C P D$ voltage drop data were subsequently converted into creep strain using appropriate formula and compared with the creep strain measured using LVDT's. It has been observed that the creep strains derived from the ACPD data match well with the creep strains measured using LVDT for all the test conditions. This study demonstrates that the ACPD technique has a potential to be employed as an effective non-destructive tool for in-situ monitoring of creep strain in components.
\end{abstract}

Keywords: ACPD; Alloy 718; Creep; Superalloy.

\section{Introduction}

Among many of the nondestructive techniques used for crack sizing and crack depth measurements, electrical potential drop (PD) technique has been proven to be the most effective tool for monitoring continuous crack growth behaviour of metals emanating from surface flaws [1-8], to estimate the depth of surface breaking flaws [9-15], to monitor corrosion and erosion of various pipes and pressure vessels [16-21], to evaluate various material properties such as conductivity and permeability [22,23] and also to monitor creep behavior of steels [24-27]. The basic principle of this technique involves the measurement of voltage drop across a surface crack of a conductive specimen on passage of electric current. Potential drop techniques have been classified into two types: direct current potential drop (DCPD) technique and alternate current potential drop (ACPD) technique. The basic difference between these two techniques lies in the fact that the current carrying capability is constrained mainly to thin surface layers to a certain depth called skin depth $(\delta)$ in the case of ACPD, whereas current distribution is uniform throughout the cross section in DCPD. Skin depth mainly depends on the applied current, frequency and material properties, such that the higher the frequency the lower the skin depth and vice versa. Skin depth estimations of various metals can be made by using an equation of the type,

$$
\delta=1 / \sqrt{ } \pi \mu \sigma \mathrm{f}
$$


Where, $\mathrm{f}$ is the frequency of the applied alternating current, $\mu$ is magnetic permeability, $\sigma$ is the electrical conductivity of the material. The main advantage of ACPD technique is its higher sensitivity. This is because the alternating current flows through a thin surface layer covering a smaller effective cross-section, instead of the whole volume/cross-section of specimen/component as in case of DCPD technique Fig. 1.

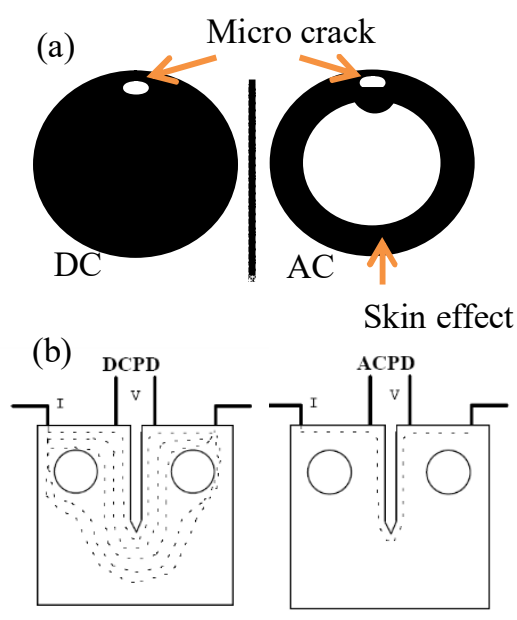

Figure.1. (a) Cross-sectional view for $\mathrm{AC}$ and $\mathrm{DC}$ in a cylindrical specimen (b) Current flow lines in Compact specimen

\begin{abstract}
Also, in ACPD a relatively low currents $\sim 0.1$ A can be used to produce large potential differences. Creep damage, one of the main phenomena occurring at high temperatures is responsible for failures of component/structures such as boilers, offshore structures, petrochemical industries and aeroengine components. Online assessment of the state of damage of a component in service is very useful in ensuring safety of structures, estimation of remaining life for life extension programs. Thus, in-situ monitoring of the progress of creep damage in such components is very important and a challenging task. This paper reports on the potential of ACPD technique to be used as NDE tool, to monitor creep strain in components in service using low frequencies. In this study an attempt has been made to correlate the strains calculated using ACPD signals recorded online during creep testing of Alloy 718.
\end{abstract}

\title{
2. Experiments
}

Alloy 718 used in this study was obtained from Mishra Dhatu Nigam Limited, Hyderabad, India in the form of $20 \mathrm{~mm}$ diameter rods in as rolled condition having the composition (wt.\%) $\mathrm{C}-0.05 \mathrm{Cr}$ 18.5 Mo-3.1 Nb-5.05 Ti-1.09 Al-0.51 Ni-52 Fe-balance. Alloy 718 was manufactured using vacuum induction melting followed by vacuum arc refining and processed through ingot metallurgy route. The specimen blanks were subjected to conventional solution treatment and double aging treatment. Solution treatment was carried out at $980{ }^{\circ} \mathrm{C}$ for 1 hour followed by air cooling. Double aging treatment involved heating to $720^{\circ} \mathrm{C}$ and holding for 8 hours followed by cooling in furnace at $55^{\circ} \mathrm{C}$ per hour to $620^{\circ} \mathrm{C}$, holding at $620^{\circ} \mathrm{C}$ for 8 hours and subsequently cooling in air to room temperature. Specimens for metallography were sectioned from the hot rolled bars using abrasive cut-off wheels. These specimens were hot mounted in bakelite molds and rough polished with dry emery papers of grade $1 / 0,2 / 0,3 / 0$ and $4 / 0$ in succession. This was followed by cloth polishing using $1 \mu \mathrm{m}$ and 0.5 $\mu \mathrm{m}$ diamond paste. To reveal the grain size and twin boundaries, chemical etching at ambient 
temperature was adopted using Kalling's reagent $(100 \mathrm{ml}$ ethanol $+100 \mathrm{ml} \mathrm{HCl}+5 \mathrm{~g} \mathrm{CuCl} 2)$ for about 10 to 20 seconds. Optical microscopy was carried out using a Leica microscope. Constant load creep tests were conducted on Alloy718 at three different test conditions i.e., $600^{\circ} \mathrm{C}(700-750 \mathrm{MPa})$, $650^{\circ} \mathrm{C}(650-750 \mathrm{MPa})$ and $700^{\circ} \mathrm{C}(600-750 \mathrm{MPa})$ as per the ASTM standard E-139. All the creep tests were conducted till fracture. The creep strains during creep tests were monitored using an extensometer mounted on the specimen and two linear variable differential transducers (LVDTs) attached to the extensometer outside the furnace. The average reading of the two LVDTs was used to plot the creep curve. Also, an alternating current potential drop equipment ( Matelect CGM-7)was used to monitor voltage drop within the gauge portion of the creep specimen. This method involves passing constant current through the gauge portion of the creep specimen and monitoring the potential drop between two points within the gauge portion near the center of the specimen. For this purpose four platinum wires were spot welded to provide four electrical connections on the specimen, two connections for current and the other two for voltage as shown in Fig.2. A constant current of 0.1 Amps and $0.3 \mathrm{kHz}$ frequency was applied to the creep specimen in the present study.

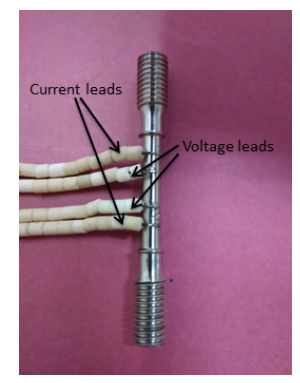

Figure.2. Creep specimen with spot welded lead connections for passing current and tapping voltage

The Matelect CGM7 is a highly specified variable-frequency dual channel alternating current potential drop system. It is housed in a portable enclosure and employs the phase sensitive detection technique to process potential drop signals generated by the passage of an internally sourced, high stability alternating current. The CGM7 can source a continuously variable alternating current of up to 5 amperes RMS over a continuously variable frequency range of 0.3 to $500 \mathrm{kHz}$. The unit is microprocessor based with set parameters accessed through a user friendly menu system and graphics screen or via a PC link to set test parameters (current, frequency, gain, filter settings and offsets). It also utilizes separate pre-amplifier units to greatly enhance signal sensitivity and immunity from extraneous sources of noise. The experimental setup to monitor crack growth using CGM7 is shown in Fig.3.

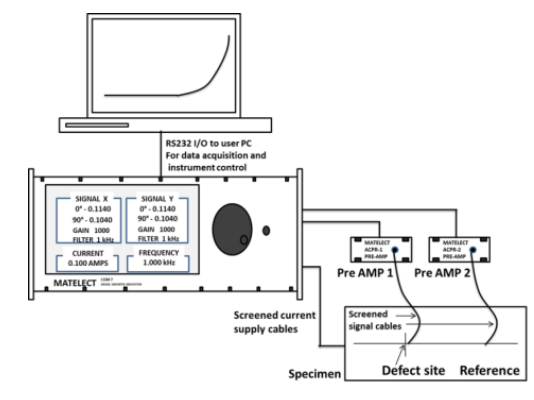

Figure.3. Showing the schematic of the ACPD setup to monitor crack growth/ creep damage using Matelect CGM7 
This ACPD equipment was used to monitor voltage drop within the gauge portion of the creep specimen during the test.

\section{Results \& Discussions}

Alloy 718 is a commercial nickel-iron based wrought superalloy. The typical microstructure of the alloy after complete heat treatment essentially consists of fine dispersion of disc shaped coherent $\gamma^{\prime \prime}(\mathrm{Ni3} \mathrm{Nb}$ type) precipitates with body centered tetragonal (BCT) structure and a small volume fraction of coherent $\gamma^{\prime}(\mathrm{Ni} 3(\mathrm{Al}, \mathrm{Ti}))$ precipitates with face centered cubic structure distributed throughout the matrix. Both these precipitates are not shown here. Also, there is a controlled amount of needle shaped delta phase at grain boundaries as shown in Fig. 4.

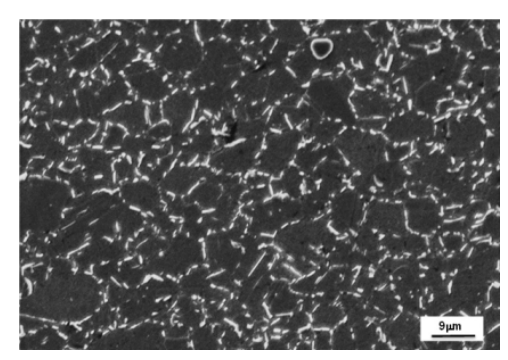

Figure.4.SEM micrograph of wrought Nickel base superalloy Alloy 718

In addition, there are $\mathrm{NbC}$ and $\mathrm{TiC}$ type carbides distributed randomly throughout the matrix (not shown here). Typical potential drop vs. time and creep strain vs. time curves of the alloy at $700^{\circ} \mathrm{C} / 600-750 \mathrm{MPa}$ are illustrated in Fig.5.
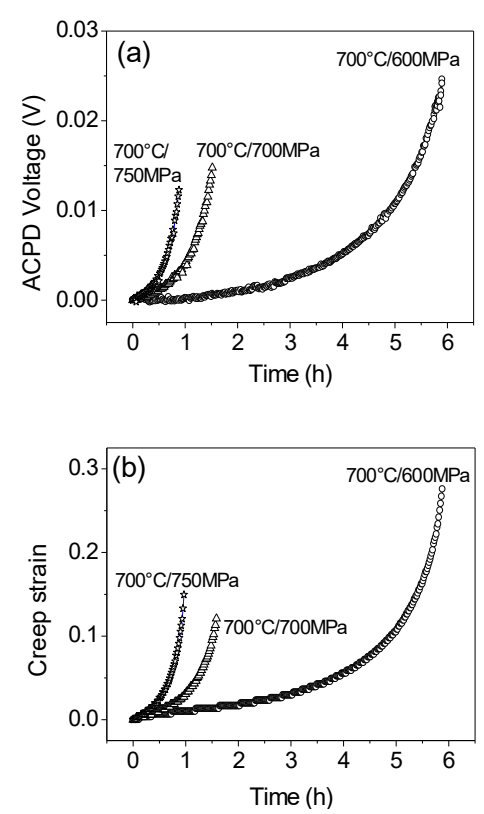

Figure.5.(a). ACPD Potential drop vs. Time (b) Creep strain vs. Time curves

It can be observed that the shape of the potential drop vs. time curve generated using ACPD is exactly similar to the creep strain vs. time plot measured using a set of linear variable differential 
transducers (LVDTs). Similar behaviour has also been observed for all other test conditions. The voltage drop across the gauge length during the test is proportional to the change in resistance of the sample during creep. This in turn depends on specimen geometry (section size and length) and resistivity. On the basis of this concept it is possible to derive a simple relationship between potential drop and creep strain so as to convert the voltage data obtained from ACPD technique to creep strain.

Let $\mathrm{A}$ be the cross sectional area and 1 be the gauge length of the specimen at any instant $\mathrm{t}$. Then electrical resistance $\mathrm{R}$ across the gauge length is given by

$$
\mathrm{R}=\rho 1 / \mathrm{A}
$$

On taking log and differentiating equation (2) with time t, one obtains the following expression, as $\rho$, resistivity is a material property, it does not vary with time hence $\rho=0$

$$
\mathrm{R} / \mathrm{R}=1 \% 1-\mathrm{A} / \mathrm{A}
$$

Also, during a creep test under tensile load the length, 1 of the specimen increases with time whereas the cross sectional area A decreases with time. The true strain rate at any instant is given

$$
\varepsilon=1 \% 1=-\mathrm{A} / \mathrm{A}
$$

On substituting equation 4 in equation 3 one gets

$$
\mathrm{R} / \mathrm{R}=2(\varepsilon)
$$

Let the initial value of resistance $\mathrm{R}$ be $\mathrm{R} 0$ and the initial strain be 0 . On integrating equation 5 and using the relation between true strain and engineering strain one gets

$$
\ln \left(\mathrm{R} / \mathrm{R}_{\mathrm{o}}\right)=2 \varepsilon=2 \ln \quad \llbracket(1+\mathrm{e}) \rrbracket(6)
$$

Since voltage drop is directly proportional to resistance at constant current the above equation gives the following relation between voltage drop and creep strain:

$$
\Delta \mathrm{R} / \mathrm{R}_{\mathrm{o}}=\Delta \mathrm{V} / \mathrm{V}_{\mathrm{o}}=2 \mathrm{e}+\mathrm{e}^{\wedge} 2
$$

On rearranging equation 7 one obtains

$$
\mathrm{e}^{\wedge}(2)+2 \mathrm{e}-\Delta \mathrm{V} / \mathrm{V}_{0}=0
$$

This is an equation of the form $a x 2+b x+c=0$, which can easily be solved. From the equation 8 , creep strain can be determined at each time from the corresponding $\Delta \mathrm{V} / \mathrm{V} 0$ value and a comparison can be made between the strain (generated from experimental creep strain obtained from LVDT) and the strain calculated from ACPD data. In Fig. 6 it is shown that the creep strain data thus derived from voltage data of ACPD technique in comparison to the creep strain data obtained using LVDTs for different test conditions for the Alloy 718. 

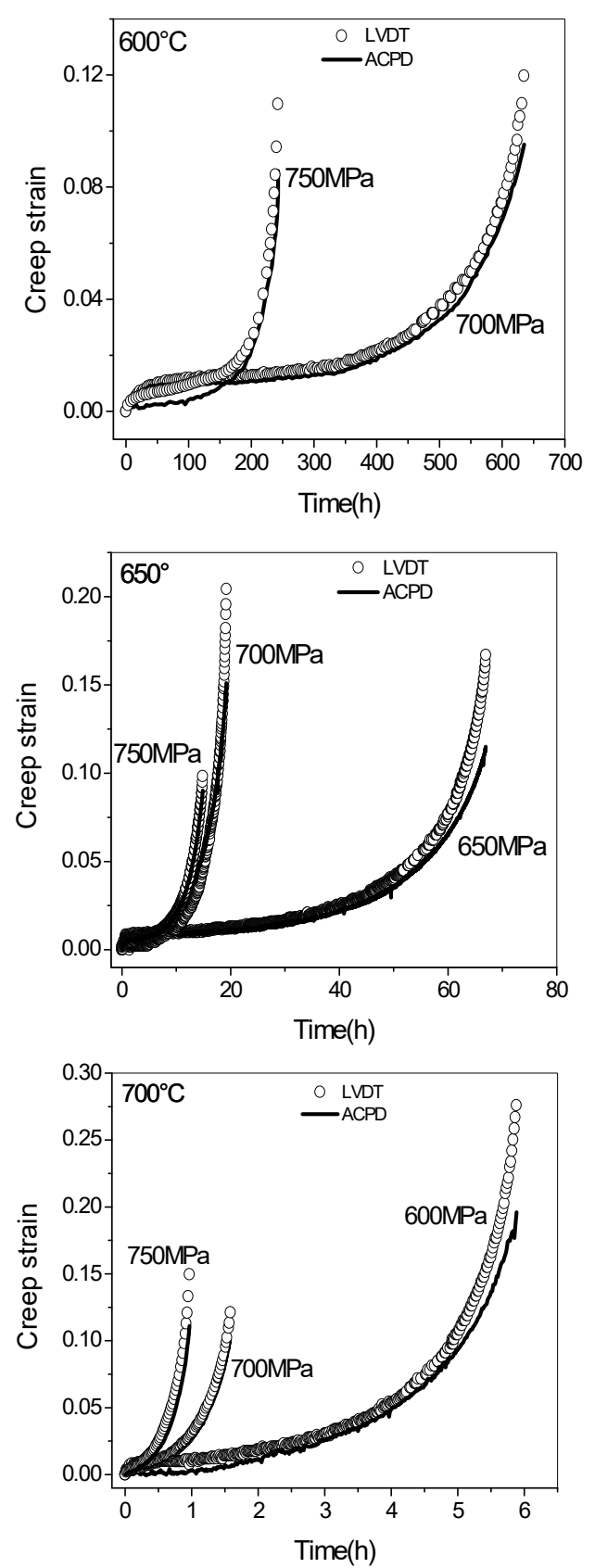

Figure.6. Showing the correlation of creep strain calculated using potential drop data obtained from ACPD technique with that measured using LVDTs for Nickel base superalloy Alloy 718 at different stress and temperature combinations

It can be observed that the creep strain data derived from ACPD technique are in reasonably good agreement with that measured using LVDTs for all test conditions, almost over the entire test period except at the times close to that of failure i.e., on the verge of failure. This could be due to the fact that the ACPD technique could not measure the strain at this point due to loss of electrical contact following specimen fracture.In most of the earlier studies, efforts have been made to use DC potential drop technique in measurements of creep deformation and damage during creep of smooth and notched specimens of IN X750 alloy [28-30] and smooth specimens of 1Cr-0.5Mo steels [31] and reported good correlation of creep strains determined by the DC potential drop technique with 
creep strains measured by LVDTs. However, such studies reporting using ACPD for determining creep strain are very limited. Recent studies using ACPD technique to monitor creep damage in steels have been reported [24-27]. However the authors were not able to correlate ACPD data with online measurements using LVDTs. In the present study, an attempt has been made to explore the potential of AC potential drop technique to monitor creep deformation in a nickel base superalloy Alloy 718.In case of ACPD technique, since skin depth for a given material and for a constant current mainly depends on the applied frequency according to equation Eq. (1), in order to ensure uniform distribution of current across the entire section of the specimen and thereby the accuracy of creep strains being measured, the optimum value of the frequency is to be determined prior to using this technique to creep strain measurement. The optimum value of frequency as determined in the present study is illustrated in Fig. 7 in the form of skin depth versus frequency plot for this alloy and is found to be about $0.3 \mathrm{kHz}$. Further, the current used in the present study is $0.1 \mathrm{~A}$, which is much lower as compared to 10-50A in DCPD technique used in several other studies [28-31].

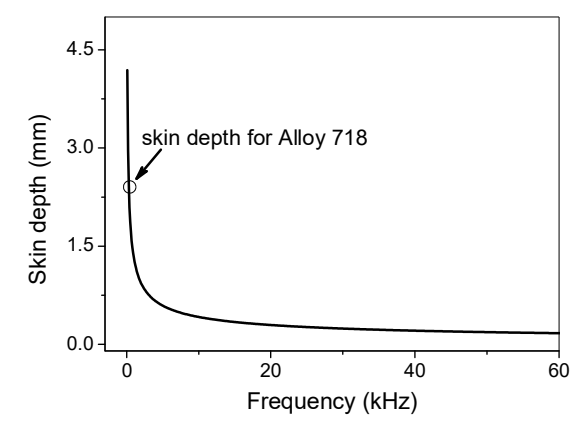

Figure.7. Skin depth versus frequency plot for Alloy 718

\section{Conclusions}

The creep strains derived from the potential drop data obtained from ACPD technique are reasonably in good agreement with the creep strains measured using LVDT during creep test of a nickel base superalloy Alloy 718 for different test conditions. This study demonstrates that the ACPD technique has a potential to be employed as an effective non-destructive tool for in-situ monitoring of creep strain in components.

\section{Acknowledgements}

The authors acknowledge the Director, Defence Metallurgical Research Laboratory, Hyderabad, for his constant support and encouragement. The authors are grateful to the DRDO for the financial assistance received. They would like to acknowledge Mr. B. Narsing Rao, for carrying out creep tests.

\section{References}

[1] Dover WD, Collins R, Michael DH, The use of AC-field measurements for crack detection and sizing in air and underwater, Philosophical Transactions of the Royal Society of London A, 320, 271$83,1986$.

[2] Venkatasubramanian TV, Unvala BA, An AC potential drop system for monitoring crack length, Journal of physics E: Scientific instruments, 17,765-71, 1984. 
[3] Ashok saxena, Electrical potential technique for monitoring subcritical crack growth at elevated temperatures, Engineering Fracture Mechanics, 13,741-750, 1980.

[4] Yasumoto Sato,Takeo Atsumi , Tetsuo Shoji, Application of induced current potential drop technique for measurement of cracks on internal wall of tube-shaped specimens, NDT\&E International, 40,497-504, 2007.

[5] Andersson M, Persson C, Melin S, Experimental and numerical investigation of crack closure measurements with electrical potential drop technique, Int J Fatigue, 28, 1059-1068,2006.

[6] Dover WD, Charlesworth FDW, Taylor KA, Collins R, Michael DH, AC field measurementstheory and practice, In: Beevers CJ,editor, The measurement of crack length and shape during fracture and fatigue, Warley, UK: Engineering Materials Advisory Service, 222-260, 1980.

[7] Thompson CD, Carey DM, Perazzo NL, Proceedings of the eighth international symposium on environmental degradation of materials in nuclear power systems -water reactors, 366-71, 1997.

[8] Mirshekar-Syahkal D, Collins R, Michael DH, The influence of skin depth on crack measurement by the AC field technique, J Nondestr.Eval, 3(2), 65-76,1982.

[9] Saguy H, Rittel D, Flaw detection in metals by the ACPD technique: theory and experiments, NDT\&E Int, 40, 505-9, 2007.

[10] Connolly MP, Michael DH, Collins R, The inversion of surface potential measurements to determine crack size and shape, Journal of Applied Physics, 64(5), 2638-47,1988.

[11] Mclver M, An inverse problem in electromagnetic crack detection, IMA Journal of Applied Mathematics, 47,127-45, 1991.

[12] Michael D, Waechter R, Collins R, The measurements of surface cracks in metals by using A.C. electric fields, R. Soc. Proc. London A, 381,139-57, 1982.

[13] Lugg MC, Data interpretation in ACPD crack inspection, NDT Int, 22(3), 149-54, 1989.

[14] Ikeda K, Yoshimi M, Miki C, Electrical potential drop method for evaluating crack depth, Int J of Fracture, 47, 25-38, 1991.

[15] Lai MO, Ng CK, Measurements of crack profiles using AC field measurement method, J of Non-Destructive Evaluation, 13(4), 155-63,1994.

[16] McMaster RC. Electric current test principles. In: McMaster RC, Editor. Nondestructive testing handbook, 1sted.columbus, OH: American society for Nondestructive testing; 35.1-35.11, 1959.

[17] Strommen RD, Horn H, Moldestad G, Ramsvik JK, Wold KR, FSM-non intrusive monitoring of internal corrosion, erosion and cracking, Anti-Corrosion methods and materials, 42(6),3-6, 1995.

[18] Kaup PG, Santosa F, Vogelius M, Method for imaging corrosion damage in thin plates from electrostatic data, Inverse problems, 12:279-93, 1996.

[19] Farrell DM, Robbins BJ, On-line monitoring of corrosion and crack growth on furnace wall tubes, In: MTI Euro TAC meeting, Brussels, 2008

[20] Giuseppe Sposito , Peter Cawley, Peter B.Nagy, Potential drop mapping for the monitoring of corrosion or erosion, NDT\&E International, 43,394-402, 2010.

[21] Y Sato,T Atsumi , T Shoji, Continuous monitoring of back wall stress corrosion cracking growth in sensitized type 304 stainless steel weldment by means of potential drop techniques, Int J pressure vessels and piping, 84,274-283, 2007.

[22] Bowler N, Huang Y, Model-based characterization of homogeneous metal plates by four-point alternating current potential drop measurements, IEEE Transactions on Magnetics, 41(6),2102-10, 2005.

[23] Bowler JR, Bowler N, Theory of four-point alternating current potential drop measurements on conductive plates, Proceedings of the Royal Society of London A, 463,817-36, 2007.

[24] Aditya Narayanan, Catrin M. Davies, Yasser K. Mahmoud, Use of the alternating current potential drop (ACPD) technique to monitor creep behaviour of austenitic steels, Proceedings of the ASME 2013 Pressure vessels and Piping Conference, July 14-18, Paris, France, 2013. 
[25] Catrin M. Davies, Peter Nagy, Aditya Narayanan, Peter Cawley, Continuous creep damage monitoring using a novel potential drop technique, Proceedings of the ASME 2011 Pressure vessels and Piping Division Conference, July 17-21, Baltimore, USA, 2011.

[26] Elhoucine Madhi, Peter B. Nagy, Sensitivity analysis of a directional potential drop sensor for creep monitoring, NDT\&E International, 44, 708-717, 2011.

[27] Seeran Prajapati, Peter B. Nagy, Peter Cawley, Potential drop detection of creep damage in the vicinity of welds, NDT\&E International, 47, 56-65, 2012.

[28] Ioannis P. Vasatis, Regis M.Pelloux, dc Potential drop technique in creep stress rupture testing, Journal of Metals ,October, 44-49, 1985.

[29] P.I.Vasatis, R.M.Pelloux, Application of the dc potential drop technique in investigating crack initiation and propagation under sustained load in notched rupture tests, Metallurgical Transactions A, Vol 19A, April, 863-871,1988.

[30] R.M.Pelloux, J.M.Peltier, V.A.Zilberstein, Creep testing of 2.25Cr-1Mo welds by DC potential drop technique, Journal of Engineering Materials and Technology, 111, 19-20, 1989.

[31] S.D.Mann, Creep strain monitoring using a d.c. potential drop technique, Materials Forum, 14, 147-150,1990. 